\title{
PERENCANAAN PENINGKATAN JALAN PADA RUAS JALAN PACITAN-NGADIROJO
}

\author{
$1^{*}$ Bakhtiar Andhi Harsono, ${ }^{2}$ Sigit Winarto, ${ }^{3}$ Yosef Cahyo S \\ ${ }^{1}$ Fakultas Teknik Universitas Kadiri

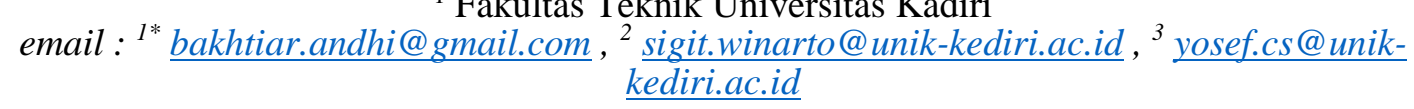

\begin{abstract}
The Pacitan-Ngadirojo road section is one of the East Java Province Roads located in Pacitan District, which includes cross-district roads. The condition of the Pacitan-Ngadirojo road segment is generally a flat road that has several bends, inclines and derivatives along the link. Passing through a number of subdistricts and villages in the Pacitan Regency area which has right and left sides, there are settlements, agricultural land, plantations, gardens, rice fields, and traditional shopping places.To analyze road performance, the writer uses the method Manual Kapasitas Jalan Indonesia (MKJI, 1997), while to calculate the thickness of road pavement, we use the method Bina Marga (1987).From the results of the road performance analysis, data were obtained as follows: Degree of Saturation (DS) on the PacitanNgadirojo road segment beginning in 2011 amounted to 0.047 while the performance analysis for the next 10 years obtained a DS of 0,078. This means that the level of road services on the road segment has not yet taken into account traffic actions or management, which in this case is road widening.For the calculation of pavement thickness with the Bina Marga Method the flexible pavement thickness on the PacitanNgadirojo road section is $7,5 \mathrm{~cm}$.
\end{abstract}

Keywords : Road Improvement Planing, Pavement Thickness, Degree of Saturation, Traffic Plan

\begin{abstract}
Abstrak
Ruas jalan Pacitan-Ngadirojo merupakan salah satu Jalan Propinsi Jawa Timur terletak di Kabupaten Pacitan, yang termasuk jalan lintas kecamatan. Kondisi ruas jalan Pacitan-Ngadirojo secara umummerupakan jalan datar yang memiliki beberapa tikungan, tanjakan dan turunan di sepanjang link tersebut. Melewati beberapa kecamatan dan desa di wilayah Kabupaten Pacitan yang sisi kanan dan kiri terdapat pemukiman, lahan pertanian, perkebunan, tegal, sawah, dan tempat perbelanjaan tradisional. Untuk analisa kinerja jalan penulis menggunakan metode Manual Kapasitas Jalan Indonesia (MKJI 1997), sedangkan untuk menghitung tebal perkerasan jalan, kami menggunakan metode Bina Marga (1987). Dari hasil analisa kinerja jalan didapatkan data-data sebagai berikut : derajat kejenuhan (DS) pada ruas jalan Pacitan-Ngadirojo awal tahun 2011 sebesar 0,047 sedangkan analisa kinerja untuk 10 tahun yang akan datang didapatkan DS sebesar 0,078. Hal ini berarti tingkat pelayanan jalan pada ruas jalan tersebut belum memerlukan adanya tindakan atau manajemen lalu lintas, yang dalam hal ini pelebaran jalan.Untuk perhitungan tebal perkerasan dengan Metode Bina Marga tebal perkerasan lentur pada ruas jalan PacitanNgadirojo setebal $7,5 \mathrm{~cm}$.
\end{abstract}

Kata Kunci : Perencanaan Peningkatan Jalan, Tebal Perkerasan, Derajat Kejenuh, Rencana Lalu Lintas 


\section{PENDAHULUAN}

Pengerasan jalan umumnya menggunakan media aspal[1][2]. Dalam proses perencaannya harus dibuat secara benar sehingga bisa membentuk sebuah jaringan jalan [3][4]. Jaringan jalan merupakan sarana transportasi darat dalam sektor perhubungan untuk kesinambungan distribusi barang dan jasa. Ketersediaan jalan yang memadai dengan kondisi yang baik, lancar, aman, nyaman dan efisien sangat diperlukan untuk menunjang laju pertumbuhan ekonomi seiring dengan meningkatnya kebutuhan sarana transportasi yang dapat menjangkau daerah-daerah yang merupakan pusat potensi ekonomi[5][6]. Kota Pacitan dan Ngadirojo mempunyai peranan penting sebagai kota pertumbuhan ekomoni dan industri. Ruas jalan Pacitan-Ngadirojo merupakan salah satu jalan Provinsi Jawa Timur terletak di kabupaten Pacitan yang termasuk jalan lintas kecamatan dalam wilayah Kabupaten Pacitan. Kondisi ruas jalan Pacitan-Ngadirojo secara umum merupakan jalan datar yang memiliki beberapa tikungan dan tanjakan di sepanjang link tersebut. Melewati beberapa Desa dan Kecamatan di wilayah Kabupaten Pacitan yang disisi kanan dan kiri terdapat pemukiman, lahan pertanian, tegal, sawah, sekolah dan tempat perbelanjaan tradisional. Wilayah Pacitan mempunyai prospek dan potensi sebagai kawasan industri pariwisata yang sangat baik sekali, mengingat pengembangan wilayah Kabupaten Pacitan serta pola distribusi wilayah tersebut sebagian besar mengarah dari dan ke Kota Pacitan yang dalam hal ini merupakan konsentrasi kegiatan perekonomian tertinggi di Kabupaten Pacitan, maka tepat sekali kalau ruas jalan Pacitan-Ngadirojo perlu ditingkatkan menjadi jalan dengan tingkat pelayanan yang baik, mantab serta nyaman. Berdasarkan studi perencanaan perkerasan jalan pada ruas jalan PacitanNgadirojo didapat data volume lalu lintas, kondisi geometrik jalan, serta data Bengkelman Beam. Dari data-data tersebut dan dengan menggunakan Metode Bina Marga menghasilkan tebal perkerasan tambahan[7][8][9][10].

\section{METODOLOGI PENELITIAN}

\subsection{Pengamatan awal}

Pengamatan awal atau observasi sangat diperlukan untuk mengetahui situasi dan kondisi ruas jalan sehingga sangat bermanfaat untuk keperluan survey lalu lintas[11][12][13].

\subsection{Studi literatur}

Studi literatur dilakukan untuk mencari definisi, dasar teori dan data-data pendukung yang relevan dengan studi saat ini yang diambil dari literatur dan kepustakaan[14].

\subsection{Perumusan masalah}

Sebagaimana dijelaskan dimuka, masalah dirumuskan untuk analisa kinerja jalan dan perencanaan perkerasan jalan[15]. 


\subsection{Pengumpulan data}

Data yang harus dikumpulkan dalam studi ini merupakan data primer, yang meliputi data volume lalu-lintas, data Benkleman Beam test, data tanah, kondisi geometrik jalan saat ini serta data sekunder[16][17].

\subsection{Pelaksanaan survey}

Sperti yang terjadi di lapangan, kondisi lalu lintas pada jam-jam tertentu cenderung tinggi dan pada jam-jam lainnya menurun kembali. Demikian pada hari-hari yang kondisi lalu lintasnya cukup tinggi[1][2][18].

\subsection{Pengolahan data}

Setelah data terkumpul kemudian dilakukan pengolahan data sesuai dengan prosedur yang diperlukan dalam analisa, yang meliputi :

1. Menganalisa kapasitas dan kinerja jalan pada lokasi studi[19][20].

2. Perencanaan perkerasan jalan dengan menggunakan metode Bina Marga 1987, perencanaan tebal lapis ulang aus dengan metode Benklemen Beam Test[21][22][4].

\section{ANALISA DAN PEMBAHASAN}

\subsection{Peta lokasi}

Perencanaan penigkatan jalan ruas jalan Pacitan - Ngadirojo tidak terlepas dari peta Jawa Timur guna mengetahui secara umum posisi perencanaan jalan tersebut.Proyek peningkatan jalan ini diambil dari titik pengenal ujung pada Pertigaan Pasar Kluwih Kecamatan Tulakan (STA 1+200) sampai Pertigaan Pucung (JLS) Hadiwarno Kecamatan Ngadirojo (STA 13+100) sepanjang $13,1 \mathrm{~km}$.

\subsection{Geometrik Jalan}

Dari hasil pengamatan yang telah penulis lakukan pada ruas Pacitan - Ngadirojo tentang geometrik jalan yang meliputi type jalan, lebar jalan dan lebar bahu jalan.

Adapun kondisi geometrik jalan kami tampilkan pada tabel 12. berikut ini :

\begin{tabular}{|c|c|c|c|c|}
\hline No. & $\begin{array}{c}\text { Nama } \\
\text { jalan }\end{array}$ & $\begin{array}{l}\text { Type } \\
\text { jalan }\end{array}$ & $\begin{array}{c}\text { Lebar } \\
\text { jalur } \\
\text { Efektif } \\
\text { WC } \\
(\mathrm{m}) \\
\end{array}$ & $\begin{array}{c}\begin{array}{c}\text { Lebar } \\
\text { bahu }\end{array} \\
\text { Efektif } \\
\text { WS } \\
\text { (m) }\end{array}$ \\
\hline 1. & $\begin{array}{l}\text { Pacitan - } \\
\text { Ngadirojo }\end{array}$ & $\begin{array}{l}2 / 2 \\
\text { UD }\end{array}$ & 6,00 & 2,00 \\
\hline
\end{tabular}

Sumber : Hasil Survey

\subsection{Data Lalu Lintas}

Untuk merencanakan tebal perkerasan pelebaran peningkatan jalan dengan memperkirakan adanya tingkat pertumbuhan rata-rata per tahun. 
Tabel 13. Pengelompokan Jenis Kendaraan

\begin{tabular}{|c|l|}
\hline Gol & Jenis kendaraan \\
\hline 1 & $\begin{array}{l}\text { Sepeda motor, sekuter dan } \\
\text { kendaraan bermotor roda } 3\end{array}$ \\
\hline 2 & Mobil penumpang 2 ton \\
\hline 3 & Minibus 3,5 ton \\
\hline 4 & Mobil hantaran 3,5 ton \\
\hline $5 \mathrm{a}$ & Bus kecil 6 ton \\
\hline $5 \mathrm{~b}$ & Bus besar 2 sumbu 9 ton \\
\hline 6 & Truk kecil 8,3 ton \\
\hline $7 \mathrm{a}$ & Truk besar 2 sumbu \\
\hline
\end{tabular}

Sumber : PUPR Kab. Pacitan

Data yang diambil berdasarkan survey volume lalu lintas pada ruas Pacitan - Ngadirojo dalam dua arah seperti terlihat dalam tabel berikut :

Tabel 14. Data Survey Lalu Lintas Rata-Rata

\begin{tabular}{|c|c|}
\hline Jenis kendaraan & LHR (2 arah) \\
& \\
\hline Gol 1 & 2200 \\
\hline Gol 2 & 625 \\
\hline Gol 3 & 415 \\
\hline Gol 4 & 325 \\
\hline Gol 5a & 110 \\
\hline Gol 5b & 14 \\
\hline Gol 6 & 285 \\
\hline Gol 7a & 12 \\
\hline
\end{tabular}

Sumber : Hasil survey

\subsection{Pertumbuhan Ekonomi dan Inflasi}

Sesuai buku PDRB yang diterbitkan BPS Kabupaten Pacitan nilai pertumbuhan ekonomi pada tahun 2017 dirata-rata tiap tahun pertumbuhan ekonomi di Kabupaten Pacitan adalah sebesar $5,25 \%$. Selanjutnya angka ini digunakan sebagai konstanta pertumbuhan arus lalu lintas (i) untuk meramalkan kinerja ruas jalan Pacitan - Ngadirojo untuk 10 tahun mendatang.

\subsection{Data Struktur Tanah}

Penyelidikan tanah pada ruas jalan Pacitan - Ngadirojo dilakukan untuk mendapatkan data keadaan tanah berupa data CBR yang digunakan sebagai bahan perencanaan untuk penyebaran jalan pada proyek peningkatan jalan. Data CBR didapatkan dari penyelkidikan DCPT (Dynamic Cone Penetration Test) yang telah dilaksanakan ditunjukkan dalam tabel dibawah ini : 
Tabel 15. nilai CBR ruas jalan Pacitan - Ngadirojo

\begin{tabular}{|c|c|c|}
\hline No. & STA & Harga CBR \\
\hline 1 & $1+200$ & 6.17 \\
\hline 2 & $2+000$ & 1.31 \\
\hline 3 & $3+000$ & 26.24 \\
\hline 4 & $4+000$ & 25.01 \\
\hline 5 & $5+000$ & 22.03 \\
\hline 6 & $6+000$ & 20.23 \\
\hline 7 & $7+000$ & 3.86 \\
\hline 8 & $8+000$ & 17.01 \\
\hline 9 & $9+000$ & 13.55 \\
\hline 10 & $10+000$ & 10.26 \\
\hline 11 & $11+000$ & 14.93 \\
\hline 13 & $12+000$ & 19.26 \\
\hline 14 & $13+000$ & 17.85 \\
\hline
\end{tabular}

Sumber : PUPR Kab. Pacitan

\subsection{Analisa Data Lalu Lintas}

Analisa data lalu lintas pada proyek Perencanaan Jalan Ruas Pacitan - Ngadirojo merupakan dasar dalam penentuan kecepatan kendaraan rata-rata, serta dapat mengetahui jumlah jenis kendaraan yang melintasi ruas jalan tersebut dalam satuan waktu, sehingga dapat diketahui lalu lintas harian rata-rata.

\subsection{Analisa Kerja Jalan}

a. Kapasitas Dasar ( Co)

Kapasitas dasar jalan dapat ditentukan dengan melihat kondisi geometrik pada segmen dan juga tipe jalan tersebut, untuk itu maka ruas jalan Pacitan Ngadirojo ini mempunnyai tipe alinyemen jalan dasar ( 2/2 UD ). Dari tabel 2.2 maka didapatkan nilai Co $=3100 \mathrm{smp} / \mathrm{jam}$.

\section{b. Faktor Penyesuaian Lebar Jalan ( FCw)}

Sesuai tabel ketentuan ruas Jalan Pacitan Ngadirojo mempunyai lebar jalur efektif 6 $\mathrm{m}$, jadi faktor penyesuaian lebar jalan adalah sebesar 0,91 .

\section{c. Faktor Penyesuaian Pemisah Arah ( FCsp)}

Faktor penyesuaian pemisah arah diperoleh dari tabel untuk tipe jalan 2/2 UD diambil pemisahan arah yang paling mendekati yaitu 50-50, sehingga didapatkan FCsp sebesar 1,00.

\section{d. Faktor Penyesuaian Hambatan Samping ( FCsf)}

Ruas jalan Pacitan Ngadirojo adalah campuran daerah pemukiman, pertokoan, pasar, fasilitas umum (seperti sekolahan, tempat peribadatan) dengan aktivitas disepanjang koridor jalan yang cukup tinggi. Nilai faktor UD didapatkan nilai FCsf sebesar 1,00.

e. Nilai Kapasitas Ruas Jalan ( C ) Kapasitas suatu jalan untuk suatu 
kondisi ditentukan faktor geometrik, volume lalu lintas dan faktor lingkungan. Untuk ruas jalanPacitan-Ngadirojo karena merupakan jalan dua lajur-dua arah tanpa median, kapasitas ditentukan untuk arus lalu lintas dua arah[23][24].

Dari persamaan maka didapatkan Nilai Kapasitas ( C )

$$
\text { Nilai } \begin{aligned}
\mathrm{C} & =\mathrm{Co} \cdot \mathrm{FCw} \cdot \mathrm{FCsp} \cdot \mathrm{FCsf} \\
& =2900 \cdot 0.91 \times 1.00 \cdot 1.00 \\
& =2639 \mathrm{smp} / \mathrm{jam}
\end{aligned}
$$

\subsection{Nilai Derajat Kejenuhan ( DS )}

Untuk menentukan derajat dibutuhkan data arus lalu lintas dalam satuan smp/jam. Dari hasil perhitungan arus lalu lintas dan kapasitas pada saat jam puncak dapat diketahui nilai derajat kejenuhan untuk ruas jalan Pacitan - Ngadirojo sebagai berikut :

Tabel 17. derajat kejenuhan

\begin{tabular}{|l|l|c|c|}
\hline \multicolumn{1}{|c|}{ Keterangan } & $\begin{array}{l}\text { Q } \\
(\mathrm{smp} / \\
\text { jam })\end{array}$ & $\begin{array}{c}\text { C } \\
(\mathrm{smp} / \\
\mathrm{jam})\end{array}$ & DS \\
\hline Awal tahun & 123,96 & 2639 & 0,047 \\
rencana 2019 & 160,06 & 2639 & 0,061 \\
\hline $\begin{array}{l}\text { Pertengahan } \\
\text { tahun rencana } \\
\text { 2024 }\end{array}$ & 206,73 & 2639 & 0,078 \\
\hline Akhir umur & & & \\
rencana 2029 & & & \\
\hline
\end{tabular}

Sumber : Perhitungan

Dengan melihat derajat kejenuhan dari kondisi awal tahun rencana sampai akhir tahun rencana 10 tahun, maka ruas jalan Pacitan - Ngadirojo masih sangat memungkinkan untuk mempertahankan perilaku lalu lintas yang diinginkan tanpa perlu adanya pelebaran jalan.

\subsection{Perencanaan Tebal Perkerasan Metode Bina Marga}

Untuk merencanakan tebal perkerasan jalan diperlukan data-data untuk menghitung tebal lapis perkerasannya.

\subsection{Data perencanaan tebal lapis perkerasan}

a. Jalan dibuka tahun $=2019$

b. Pertumbuhan lalu lintas (i) $=5.25 \%$ 
c. Umur Rencana (UR) $=10$ tahun

d. Direncanakan bahan yang digunakan untuk lapis perkerasan : Laston

e. Tipe jalan yang digunakan adalah 1 lajur 2 arah tanpa median (2/2 UD)

\subsection{Lalu Lintas Rencana}

Data lalu lintas rencana (LHR) adalah data sekunder, yang diperoleh dari hasil survey.

Tabel 18. Data Survey Lalu Lintas Rata-Rata

\begin{tabular}{|c|c|}
\hline Jenis kendaraan & LHR (2 arah) \\
\hline Gol 1 & 2200 \\
\hline Gol 2 & 625 \\
\hline Gol 3 & 415 \\
\hline Gol 4 & 325 \\
\hline Gol 5a & 110 \\
\hline Gol 5b & 14 \\
\hline Gol 6 & 285 \\
\hline Gol 7a & 12 \\
\hline
\end{tabular}

Sumber : Hasil survey

Dari data lalu lintas tersebut dapat dihitung nilai LHR akhir umur rencana 2029.

Tabel 19. Arus Lalu Lintas Akhir Umur Rencana

\begin{tabular}{|c|c|c|c|}
\hline Kend & LHR & emp & Q (smp) \\
\hline Gol 1 & 3670 & 0.5 & 1835,0 \\
\hline Gol 2 & 1043 & 1 & 1043,0 \\
\hline Gol 3 & 692 & 1 & 692,0 \\
\hline Gol 4 & 542 & 1 & 542,0 \\
\hline Gol 5a & 183 & 1 & 183,0 \\
\hline Gol 5b & 23 & 1 & 23,0 \\
\hline Gol 6 & 475 & 1.3 & 617,5 \\
\hline Gol 7a & 20 & 1.3 & 26,0 \\
\hline \multicolumn{2}{|c|}{ Q smp/jam } & 206,73 \\
\hline
\end{tabular}

Sumber : Perhitungan

\subsection{Koefisien Distribusi Kendaraan}

Jalur kendaraan pada ruas jalan Pacitan-Ngadirojo ini berjenis 2 jalur 2 arah tanpa median (2/2 UD), sehingga berdasarkan tabel, nilai Koefisien Distribusi Kendaraan (C) bernilai 0,5. 


\subsection{Angka Ekivalen (E) Beban Sumbu Kendaraan}

Berikut adalah hasil perhitungan untuk Angka Ekivalen (E) seluruh jenis kendaraan.

Tabel 20. Angka Ekivalen (E)

\begin{tabular}{|c|c|c|}
\hline No & Jenis & Angka \\
& Kendaraan & Ekivalen (E) \\
\hline 1 & Gol.2 & 0,0004 \\
\hline 2 & Gol.3 & 0,0042 \\
\hline 3 & Gol.4 & 0,0068 \\
\hline 4 & Gol.5a & 0,0593 \\
\hline 5 & Gol.5b & 0,0438 \\
\hline 6 & Gol.6a & 0,2174 \\
\hline 7 & Gol.7a & 0,6437 \\
\hline
\end{tabular}

Sumber :Hasil perhitungan

\subsection{Lintas Ekivalen Kendaraan}

Dari data LHR akhir umur rencana, Koefisien Distribusi Kendaraan (C), dan Angka Ekivalen (E). Bisa menghitung Lintas Ekivalen Permulaan (LEP) dan Lintas Ekivalen Akhir (LEA). Berikut adalah hasil perhitungan LEP dan LEA untuk semua jenis kendaraan.

Tabel 21. berikut.

\begin{tabular}{|c|c|c|c|}
\hline No & Jenis & LEP & LEA \\
\hline 1 & Kendaraan & 0,125 & 0,2086 \\
\hline 2 & Gol.2 & 0,8715 & 1,4532 \\
\hline 3 & Gol.3 & 1,105 & 1,8428 \\
\hline 4 & Gol.4 & 32,615 & 54,2595 \\
\hline 5 & Gol.5a & 0,3066 & 0,5037 \\
\hline 6 & Gol.5b & 30,9795 & 51,6325 \\
\hline 7 & Gol.6a & 3,8622 & 6,437 \\
\hline & Gol.7a & 69,8648 & $\mathbf{1 1 6 , 3 3 7 3}$ \\
\hline
\end{tabular}

Sumber : Hasil perhitungan 


\subsection{Lintas Ekivalen Rencana (LER)}

Setelah mendapatkan nilai LET dapat dicari nilai Lintas Ekivalen Rencana (LER) dengan persamaan berikut ini.

\section{LER}

$$
=\mathrm{LET} \cdot \mathrm{FP}
$$

Faktor penyesuaian (FP) ditentukan dengan rumus :

FP

$$
\begin{aligned}
& =\mathrm{UR} / 10 \\
& =\mathrm{LET} \cdot \mathrm{UR} / 10 \\
& =93,1011 \cdot 10 / 10 \\
& =93,1011
\end{aligned}
$$

\subsection{Indeks Tebal Perkerasan (ITP)}

Dari nilai IPo 3,9 - 3,5 dan IPt 2,0 maka menggunakan nomogram nomor 4. Kemudian nilai Indeks Tebal Perkerasan (ITP) dapat ditentuk an dengan memasukkan data-data berikut kedalam nomogram 4:
a. $\mathrm{DDT}=5,85$
b. LER $=93,1011$
c. $\mathrm{FR}=1$
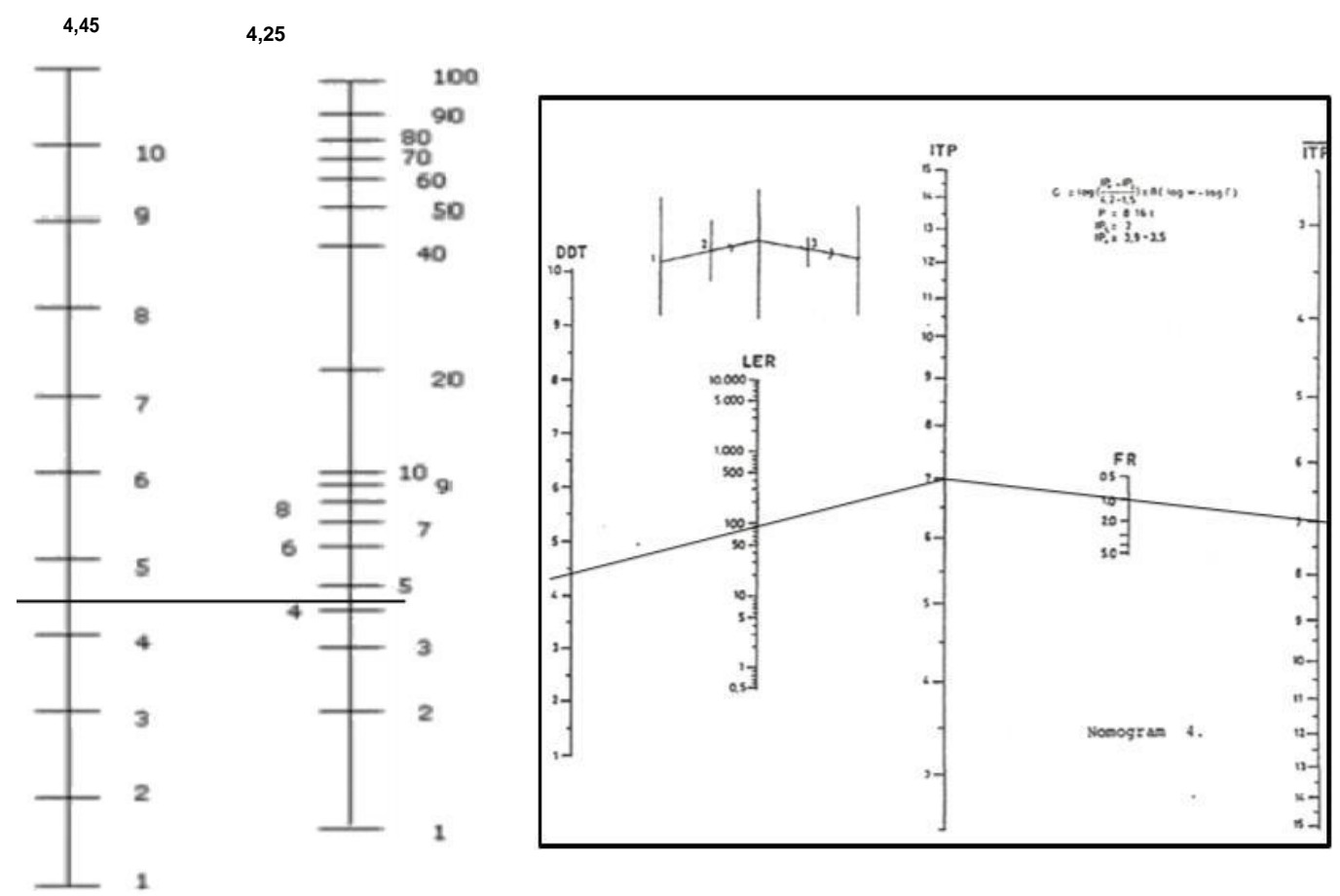

Gambar 2. grafik Hubun gan DDT dan CBR

\subsection{Faktor Regional Pada}

Faktor Regional diperlukan data curah hujan, persen kelandaian jalan, dan persen kendaraan berat. Berikut data-data sekunder yang di dapatkan dari Dinas Pekerjaan Umum Bina Marga Kabupaten Pacitan.

Curah hujan $=90,76 \mathrm{~mm} / \mathrm{th}$ 
Persen Kelandaian $\quad=6 \%$

Kendaraan Berat $\quad=24,7 \%$

dari data sekunder diatas dapat ditentukan nilai Faktor Regional (FR) pada ruas jalan Pac itanNgadirojo adalah 1 .

\subsection{Tebal Lapis Perkerasan}

Lapis Permukaan direncanakan menggunakan Laston se hingga tebal minimum (D1) yang diijinkan dengan nilai ITP 7 adalah 7,5 cm.

\section{KESIMPULAN DAN SAR AN}

\subsection{Kesimpulan}

Hasil analisa perencanaan jalan (2/2 UD) utk pertumbuhan lalu lintas rata-rata (i) $=6 \%$ diperoleh Derajat Kejenuhan (DS) = 0,38 akhir umur rencana 10 tahun, sehingga ruas jalan yang diremcanakan belum memerlukan pelebaran jalan.

\subsection{Saran}

1. Peningkatan Jalan Ruas Pacitan - Ngadirojo sebaiknya dilakukan perawatan secara berkala sehingga dapat berfungsi selama umur rencana bahkan lebih.

2. Mengingat pertumbuhan ekonomi yang berdampak pada penigkatan arus lalu lintas dan juga kondisi jalan saat ini, maka ruas jalan Pacitan-Ngadirojo selayaknya diadakan lapis tambahan.

3. Perbaikan bahu jalan disisi kiri dan kanan dengan perkerasan yang sesuai dengan kebutuhan, agar kendaraan yang berhenti atau parkir mendapatkan ruang.

\section{UCAPAN TERIMAKASIH}

Dalam penyusunan artikel ini, penulis ucapkan terimakasih kepada dosen pembimbing dan Universitas Kadiri. Penulis berharap agar artikel ini dapat bermanfaat bagi pembaca.

\section{DAFTAR PUSTAKA}

[1] R. Ananda and D. P. Retno, "Evaluasi Perencanaan Geometrik Pada Ruas Jalan Lubuk Sakat-Teluk Petai Pada km 2-km 4, 8 Kabupaten Kampar,” J. Saintis, vol. 14, no. 2, pp. 54-65, 2014.

[2] S. L. Hendarsin, "Perencanaan Teknik Jalan raya," Politek. Negeri Bandung, 2000.

[3] F. A. Lestari and Y. Apriyani, "ANALISIS DAMPAK LALU LINTAS AKIBAT ADANYA PUSAT PERBELANJAAN DIKAWASAN PASAR PAGI PANGKALPINANG TERHADAP KINERJA RUAS JALAN," J. Fropil, vol. 2, no. 1, pp. 32-44, 2014.

[4] B. Javilla, H. Fang, L. Mo, B. Shu, and S. Wu, "Test evaluation of rutting performance 
indicators of asphalt mixtures," Constr. Build. Mater., vol. 155, pp. 1215-1223, 2017, doi: 10.1016/j.conbuildmat.2017.07.164.

[5] B. C. Fambella, R. Sulaksitaningrum, M. Z. Arifin, and H. Bowoputro, "Evaluasi dan Perencanaan Geometrik Jaringan Jalan di Dalam Universitas Brawijaya Malang,” J. Mhs. Jur. Tek. Sipil, vol. 1, no. 3, p. pp-1146, 2015.

[6] G. Sugiyanto, "Marshall test characteristics of asphalt concrete mixture with scrapped tire rubber as a fine aggregate," J. Teknol., vol. 79, no. 2, pp. 55-64, 2017, doi: 10.11113/jt.v79.6965.

[7] W. Hu, X. Jia, B. Huang, and H. Park, "Evaluation of compactability of asphalt mixture utilizing asphalt vibratory compactor," Constr. Build. Mater., vol. 139, pp. 419-429, 2017, doi: 10.1016/j.conbuildmat.2017.02.070.

[8] Departemen Pekerjaan Umum, "Petunjuk Perencanaan Tebal Perkerasan Lentur Jalan Raya Dengan Metode Analisa Komponen,” 1987.

[9] A. D. Limantara, A. I. Candra, and S. W. Mudjanarko, "Manajemen Data Lalu Lintas Kendaraan Berbasis Sistem Internet Cerdas Uji coba Implementasi Di Laboratorium Universitas Kadiri,” Semnastek, no. November, pp. 1-2, 2017.

[10] E. Nurfadzilah, S. Winarto, and Y. Cahyo, "ANALISA JALAN RING ROAD NGAWI STA 3+200 - STA 6+200 KABUPATEN NGAWI PROPINSI JAWA TIMUR," Jurmateks, vol. 1, no. 1, pp. 33-43, 2018.

[11] S. Silvia, "Dasar-dasar Perencanaan Geometrik Jalan," Penerbit Nova. Bandung, 1994.

[12] B. Marga, "Tata Cara Perencanaan Geometrik Jalan Antar Kota," Direktorat Pembin. Jalan Kota. Jakarta, 1997.

[13] R. Yuwono, Y. C. Sp, and L. D. K, "STUDY ANALISA VOLUME KENDARAAN PADA SIMPANG BERSINYAL DI PEREMPATAN ALUN ALUN KOTA KEDIRI," Jurmateks, vol. 1, no. 1, pp. 101-111, 2018.

[14] D. P. U. SKBI-2.3. 26. 1987, UDC: 625.73 (02), "Petunjuk Perencanaan Komponen Tebal Perkerasan Lentur Jalan Raya Dengan Metode Analisa Jalan,” Peratur. Perenc. Geom. Jalan Raya, no. 13, 1970.

[15] D. Pribadi, M. J. Paransa, T. K. Sendow, and L. J. Undap, "Tinjauan geometrik jalan pada ruas Jalan Airmadidi-Tondano menggunakan alat bantu GPS," J. Sipil Statik, vol. 1, no. 7, 2013.

[16] H. Fithra, "PENGARUH JUMLAH TUMBUKAN PADA CAMPURAN ASPHALT CONCRETE WEARING COURSE (AC-WC) TAMBAHAN LATEKS TERHADAP SIFAT MARSHALL,” Teras J., 2017.

[17] R. T. Bethary and M. F. Pradana, "PERENCANAAN GEOMETRIK JALAN 
ALTERNATIF PALIMA-CURUG ((Studi Kasus: Kota Serang)," J. Fondasi, vol. 5, no. 2, 2016.

[18] J. McNulty, "PEMANFAATAN LIMBAH BETON SEBAGAI PENGGANTI AGREGAT KASAR PADA CAMPURAN ASPHALT CONCRETE-WEARING COURSE GRADASI KASAR Arys,” vol. 66, no. 1997, pp. 37-39, 2013.

[19] D. P. Umum, "SNI 03-1969-1990," Metod. Penguji. Berat Jenis Dan Penyerapan Air Agreg. Kasar, 1990.

[20] L. Gupta and A. Bellary, "Comparative study on the Behavior of Bituminous Concrete Mix and Warm Mix Asphalt Prepared Using Lime and Zycotherm as Additive," Mater. Today Proc., vol. 5, no. 1, pp. 2074-2081, 2018, doi: 10.1016/j.matpr.2017.09.203.

[21] D. D. B. Marga, “Tata Cara Perencanaan Geometrik Jalan Antar Kota," Dirjen DPU Bina Marga, 1997.

[22] E. Masad, B. Muhunthan, N. Shashidhar, and T. Harman, "Internal structure characterization of asphalt concrete using image analysis," J. Comput. Civ. Eng., vol. 13, no. 2, pp. 88-95, 1999, doi: 10.1061/(ASCE)0887-3801(1999)13:2(88).

[23] Dinas Pekerjaan Umum Direktorat Jenderal Bina Marga, Manual Perkerasan Jalan Dengan Alat Benkelmen Beam No. 01/MN/BM/83. Jakarta: Yayasan Badan Penerbit PU, 1983.

[24] Departemen Pekerjaan Umum, Metode AASTHO 1972. Jakarta: Yayasan Badan Penerbit PU, 1972. 